\title{
Paget-Schroetter syndrome in the absence of common predisposing factors: a case report
}

\author{
Ramy Ibrahim ${ }^{1}$, Irina Dashkova², Myia Williams ${ }^{3^{*}} \mathbb{D}$, Andrzej Kozikowski $^{4}$, Neeraj Abrol ${ }^{5}$, Anjula Gandhi ${ }^{6}$
} and Renee Pekmezaris ${ }^{7}$

\begin{abstract}
Background: Paget-Schrotter Syndrome (PSS) also known as "effort thrombosis" is a form of primary thrombosis in the subclavian vein at the costoclavicular junction is usually seen in younger patients after repeated strenuous activity of the shoulders and arms. When occurring in younger patients, PSS presents itself with predisposing factors such as unilateral dull, aching pain in the shoulder or axilla and swelling of the arm and hand.

Case Presentation: We report a rare case of unusual left axillo-subclavian vein thrombosis in absence of clear risk factors and a negative hypercoagulable workup in a 36-year-old Hispanic woman who presented with 2 days duration of left upper extremity pain and swelling after a week of heavy exercise in aerobic class. Very few documented cases of primary or spontaneous ASVT in absence of clear factors and in such anatomical location have been previously reported.

The patient was started on strict precautions of left upper extremity immobilization, analgesics in the form of Tylenol $650 \mathrm{mg}$ every $6 \mathrm{~h}$ for pain as well as cold compresses. Lovenox $90 \mathrm{mg}$ subcutaneous twice daily (1 mg/ kg BID) was started together with warfarin to keep INR 2-3.

Conclusion: In addition to the unusual location in the left upper extremity in our case, the absence of common etiologic factors makes our case of Paget-Schroetter Syndrome a very unique one. Presently, there is a lack of guided management of rare conditions such as our case, or consensus among the sources. Physicians should be aware of this rare disease since untreated conditions may be debilitating for the patient and very costly especially if diagnosed with a delay.
\end{abstract}

Keywords: Deep Vein Thrombosis, Paget-Schrotter Syndrome, Axillary-subclavian venous thrombosis, Pulmonary Embolism, Thrombosis, Upper Extremity Deep Vein Thrombosis

\section{Background}

Paget- Schroetter Syndrome involves axillary-subclavian venous thrombosis (ASVT) associated with strenuous and repeated activity of the upper extremities $[1,2]$. PSS is also called "effort" thrombosis denoting that the syndrome often occurs in physically active individuals after unusual strenuous use of the arm and shoulder [3]. In addition, PSS is also referred to as "spontaneous" ASVT, highlighting its often dramatic, unexpected presentation in otherwise healthy young individuals $[4,5]$. On average,

\footnotetext{
* Correspondence: mwilliam26@northwell.edu

${ }^{3}$ Department of Medicine, Northwell Health, New York, USA

Full list of author information is available at the end of the article
}

PSS accounts for at least 10-20\% of upper extremity deep thrombosis and at least up to $30-40 \%$ of spontaneous axillary-subclavian venous thrombosis $[1,2]$.

PSS is usually experienced after sporting activities such as swimming, wrestling and gymnastics which often involve vigorous and continued movements of the upper extremity [2]. It is believed that retroversion, hyperabduction and extension of the arm involved in strenuous sporting activities impose undue strain on the subclavian vein; which leads to micro-trauma of the endothelium and activation of the coagulation cascade. Consequently, it is not unusual that PSS usually occurs in the dominant arm of young, healthy and active men [2]. Patients with 
Table 1 Manifestations of DVT

Type of Manifestation

Asymptomatic

Pain in the arm, neck and shoulder region Diffuse arm swelling

Discoloration, tenderness and distension on the affected limb

Visible collaterals on the affected arm Arm discoloration and palpable vessels

PSS are customarily symptomatic, with swelling and arm discomfort being the most frequently reported and presented problems, as shown in Table 1 [2, 6-8]. Other symptoms reported include heaviness, redness of arm, cyanosis and dilated, visible veins across the shoulder and upper arm (Urschel's sign) [2, 6]. Often the symptom onset is either acute or sub-acute, however, occasionally, patients can present with chronic symptoms [2]. In addition, not uncommon symptoms can present as nonspecific and at times mimic those of a muscular strain $[2,9]$. Further, a majority of patients have reported a discrete precipitating event of a sports related arm exertion. Similarly, trivial and harmless daily activities can result in PSS $[2,6,10]$.

Complications also seen in patients with PSS include pulmonary embolism (PE), post thrombotic syndrome and recurrent thrombosis $[2,6,7]$. It is important to note there are mixed reports of lower incidence of $\mathrm{PE}$ in upper extremity DVT when compared with lower extremity DVT and catheter related UEDVT [2, 8, 11, 12]. Regardless, health practitioners should bear in mind that the risk of PE in patients with PSS is real and significant $[2,6,7,13,14]$.

We report a rare case of unusual left axillosubclavian vein thrombosis in absence of clear risk factors and a negative hypercoagulable workup in a 36-year-old Hispanic woman who presented with 2 days duration of left upper extremity pain and swelling after a week of heavy exercise in aerobic class. Very few documented cases of primary or spontaneous ASVT in absence of clear factors and in such anatomical location have been previously reported.

\section{Case presentation}

A 36 year old apparently healthy Hispanic female presented to the emergency department (ED) with a 4 days history of left upper extremity pain dull aching in nature and tenderness to palpation after a week of strenuous activity. Her background history was without any significant family history or risk factors. Physical examination revealed a moderately nourished, well-built female, not in acute distress except for marked pain in left extremity. No other abnormality was detected on physical examination.

A complete blood count was done as part of a routine examination. Doppler studies of the four extremities was done in ED which showed left axillosubclavian acute DVT. Laboratory results are presented in Table 2 and Table 3 below. Secondary to the elevated D-Dimers patient underwent CT chest and pulmonary angiography to rule out pulmonary extension or pulmonary embolism (PE). The CT results confirmed the presence of left axillo-subclavian venous thrombosis; however, there was no evidence of $\mathrm{PE}$.

Futhermore, a CT chest was done and results showed there were no anatomical abnormalities obstructing thoracic outlet. It is possible that strenuous physical activity with temporary obstruction of the thoracic outlet while patient was training her upper body has triggered and likely temporary dehydration caused by extensive sweating during physical training further contributed to the thrombotic event.

The patient was started on strict precautions of left upper extremity immobilization, analgesics in the form of Tylenol $650 \mathrm{mg}$ every $6 \mathrm{~h}$ for pain as well as cold compresses. Lovenox $90 \mathrm{mg}$ subcutaneous twice daily $(1 \mathrm{mg} / \mathrm{kg}$ BID) was started together with warfarin to keep INR 2-3. On the third day of hospitalization the therapeutic INR was reached and patient was discharged.

Additional workup to exclude hypercoagulable state in the form of antiphospholilpid antibody, factor V, Leyden, protein $\mathrm{S}$ and $\mathrm{C}$ and antithrombin III were within normal levels with no gross abnormality suggestive of thrombophilic state. Catheter-guided thrombolysis was considered

Table 2 Initial Admission Laboratory Results

\begin{tabular}{lll}
\hline Parameter & Values & Range \\
\hline WBC & 6.2 & $4-11$ \\
RBC & 3.63 & $3.8-5.3$ \\
HCT & 32 & $37-51$ \\
MCV & 88.1 & $80-101$ \\
MCHC & 30.8 & $27-32$ \\
RDW & 12.6 & $11.5-14.5$ \\
Platelet & 244 & $130-450$ \\
D-dimer & 2203 & $0-278$ \\
BUN & 15 & $8-25$ \\
Creatinine & 0.7 & $0.5-1.04$ \\
Sodiun & 138 & $133-145$ \\
Potassium & 4.4 & $3.5-5.5$ \\
Chloride & 101 & $96-101$ \\
Carbon dioxide & 27 & $22-28$ \\
Calcium & 9.4 & $8.5-10.5$ \\
Antithrombin III & 113 & $85-120$ \\
Protein C & 110 & $70-180$ \\
Lupus anticoagulant & 45 & $<40$ \\
Proteins & 94 & $60-140$ \\
\hline
\end{tabular}


Table 3 Risk factors for Paget-Schroetter Syndrome

Risk Factors
inysical activity involving hyperabduction of the shoulder, as seen
Motions often associated with tennis players and baseball pitchers
Vigorous exercise of the neck and upper extremity muscles
Overdeveloped anterior scalene muscle Rudimentary first rib
Presence of cervical rib
Congenital band between first and second ribs Fracture of the
clavicle with callus formation
Apical tumors of the superior sulcus of the lung (Pancoast tumor)
Thoracic outlet syndrome

with option to transfer patient to specialized center since this type of treatment was not available at the described facility. However patient was not willing to relocate and preferred to be treated at the same facility she was admitted to originally knowing that other type of treatment is available at the other center.

Two months after discharge, patient came for follow up. Doppler study showed that there were no blood clots in axillosubclavian vessels and all blood work was within normal limits including D-Dimers of 177 and the patient clinically asymptomatic.

\section{Discussion and conclusions}

In this report, we have noticed a relatively uncommon presentation of DVT in the upper extremity in absence of any common risk factor.

Stress thrombosis or primary ASVT syndrome can occur in apparently healthy individuals without Virchow's triad or other thrombosis enhancing risk factors. How can thrombosis occur in patients without any apparent predisposition? The exact mechanism of this is not well understood, however, it may be related to minor thoracic inlet abnormalities together with strenuous physical activity which defies the state of stasis in Virchow's triad. The abnormalities of the thoracic outlet are often bilateral and predispose to eventual thrombosis of both venous systems [15]. In addition, chronic compression of the vein can cause perivenous fibrosis, which may result in partial venous obstruction despite surgical correction of the compressing lesion $[15,16]$. In our case 2 months after hospitalization patient treated with anticoagulation with Warfarin came for a follow up. Her symptoms were resolved so to were blood clot in axillosubclavian veins.

Condition management should include differential diagnosis such as cellulitis, lymphedema, neoplastic compression of veins, traumatic muscle injury, and thrombosis of superficial veins. A detailed imaging panel including dopplers, CT angiography and even MRI/MRA must be considered. Laboratory testing should include $\mathrm{CBC}$ with special focus on platelet count to exclude other etiologies, as well as a complete panel of hypercoagulable work up to exclude secondary causes [17]. Should clinical picture suggest ASVT, the best test to perform first is the duplex sonogram. It is inexpensive, highly sensitive, specific and non-invasive way to diagnose condition without delay of treatment.

Patients may have good prognosis and better outcome of thrombolytic therapy, if ASVT was diagnosed early, and extent of damages is limited. In case of skeletal abnormality, compressing venous structures as a cause of ASVT, surgical intervention such as rib or clavicle resection may be needed. Rehabilitation and physical therapy are an important part of patient's management, even more so in case of purely muscular causes of venous blood flow obstruction.

Acute deep venous thrombosis is a very common problem affecting up to one in every thousand Americans; however, upper extremity presentation is much less common. Excluding surgical causes, catheter-induced upper extremity venous thrombosis becomes a rare presentation. However by further excluding secondary causes only very few cases of primary upper extremity DVT or PSS have been reported. As a result, more research is needed in ASVT. Presently, there is a lack of guided management of rare conditions such as our case, or consensus among thesources. Physicians should be aware of this rare disease since untreated conditions may be debilitating for the patient and very costly especially if diagnosed with a delay. Absence of anatomical obstruction and favorable outcome after conventional treatment makes this case unique.

\section{Abbreviations \\ ASVT: Axillary-subclavian venous thrombosis; CBC: Complete Blood Clot; DVT: Deep Vein Thrombosis; ED: Emergency department; INR: International Normalised Ratio; MRA: Magnetic Resonance Angiogram; MRI: Magnetic Resonance Imaging; PE: Pulmonary embolism; PSS: Paget-Schrotter Syndrome; UEDVT: Upper Extremity Deep Vein Thrombosis}

\section{Acknowledgements}

We thank everyone involved for their kind support during this work.

\section{Availability of data and materials}

Please contact author for data requests.

\section{Funding}

None.

\section{Authors' contributions}

$\mathrm{RI}, \mathrm{ID}, \mathrm{NA}, \mathrm{AG}$ worked on interpreting and analyzing patient data as well as writing of the article. MW, AK and RP worked on writing the article and critical revision of the article. All authors were major contributors. All the authors of this paper have reviewed the document in its entirety and are in agreement with the structure and content. All authors read and approved the final manuscript.

Ethics approval and consent to participate

Patient gave her consent to be in this study/case report.

Consent for publication

The patient gave her consent for the publication of this study. 


\section{Competing interests}

The authors declare that they have no competing interests.

\section{Publisher's Note}

Springer Nature remains neutral with regard to jurisdictional claims in published maps and institutional affiliations.

\section{Author details}

${ }^{1}$ Premier Medical Associates Group Orlando, Florida, USA. ${ }^{2}$ Division of Geriatric and Palliative Medicine, Northwell Health, New York, USA. ${ }^{3}$ Department of Medicine, Northwell Health, New York, USA. ${ }^{4}$ Department of Medicine, Northwell Health, NewYork, USA. ${ }^{5}$ Attending Physician, Brookdale Hospital, New York, USA. 'Internal Medicine Residency Program, Brookdale Hospital, New York, USA. 'Department of Medicine, Northwell Health, New York, USA

Received: 3 April 2017 Accepted: 12 July 2017

Published online: 01 August 2017

\section{References}

1. Dep A, et al. Paget-Schrotter syndrome and complications of management. BMJ Case Rep. 2013;(2013): bcr2013008858.

2. Alla VM, et al. Paget-Schroetter syndrome: review of pathogenesis and treatment of effort thrombosis. Western Journal of Emergency Medicine. 2010;11(4):358-62.

3. von Schroetter L. Erkrankungen der Gefasse. In: Nathnagel Handbuch der Pathologie und Therapie, Anonymous Wein, Holder; 1884.

4. Martinelli I, Mannucci PM, De Stefano V, et al. Different risks of thrombosis in four coagulation defects associated with inherited thrombophilia: a study of 150 families. Blood. 1998:92:2353.

5. Mustafa S, Stein PD, Patel KC, et al. Upper extremity deep venous thrombosis. Chest. 2003;123:1953.

6. Urschel HC Jr, Patel AN. Surgery remains the most effective treatment for Paget-Schroetter syndrome: 50 years' experience. Ann Thorac Surg. 2008:86:254-60

7. Kommareddy A, Zaroukian MH, Hassouna HI. Upper extremity deep venous thrombosis. Semin Thromb Hemost. 2002;28:89-99.

8. Joffe HV, Kucher N, Tapson VF, et al. Upper-extremity deep vein thrombosis: a prospective registry of 592 patients. Circulation. 2004;110:1605-11.

9. Louis J. Axillary vein thrombosis mimicking muscular strain. J Accid Emerg Med. 1999;16:233-4

10. Zell L, Kindermann W, Marschall F, et al. Paget-Schroetter syndrome in sports activities-case study and literature review. Angiology. 2001;52:337-42

11. Kooij JD, van der Zant FM, van Beek EJ, et al. Pulmonary embolism in deep venous thrombosis of upper extremity: more often in catheter-related thrombosis. Neth J Med. 1997:50:238-42.

12. Monreal M, Lafoz E, Ruiz J, et al. Upper-extremity deep venous thrombosis and pulmonary embolism. A prospective study. Chest. 1991;99:280-3.

13. Prandoni $P$, Polistena $P$, Bernardi $E$, et al. Upper-extremity deep vein thrombosis. Risk factors, diagnosis, and complications. Arch Intern Med. 1997;157(1):57-62

14. Elman EE, Kahn SR. The post-thrombotic syndrome after upper extremity deep venous thrombosis in adults: a systematic review. Thromb Res. 2006;117:609-14.

15. Prandoni $\mathrm{P}$, Polistena $\mathrm{P}$, Bernardi $\mathrm{E}$, et al. Upper-extremity deep vein thrombosis. Risk factors, diagnosis, and complications. Arch Intern Med. 1997;157:57.

16. HUGHES ES. Venous obstruction in the upper extremity; Paget-Schroetter's syndrome; a review of 320 cases. Surg Gynecol Obstet. 1949;88:89

17. Qaseem A, Snow V, Barry P, et al. Current diagnosis of venous thromboembolism in primary care: a clinical practice guideline from the American Academy of family physicians and the American College of Physicians. Ann Intern Med. 2007;146:454

\section{Submit your next manuscript to BioMed Central and we will help you at every step:}

- We accept pre-submission inquiries

- Our selector tool helps you to find the most relevant journal

- We provide round the clock customer support

- Convenient online submission

- Thorough peer review

- Inclusion in PubMed and all major indexing services

- Maximum visibility for your research

Submit your manuscript at www.biomedcentral.com/submit 